\title{
Games and Play in the Creative, Smart and Ecological City
}

\section{Edited by Dale Leorke and Marcus Owens}

\section{Promoting Yokosuka through videogame tourism}

The Shenmue Sacred Spot

Guide Map

Carlos Ramírez-Moreno and Dale Leorke

(CC BY-NC-ND 4.0)

This OA chapter is funded by Tampere University

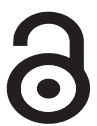

Routledge

Taylor \& Francis Group 


\title{
3 Promoting Yokosuka through videogame tourism
}

\author{
The Shenmue Sacred Spot \\ Guide Map
}

Carlos Ramírez-Moreno and Dale Leorke

\section{Introduction}

There is a growing body of academic literature on cultural tourism, especially focusing on instances where organisations across different levels of government have capitalised on the incorporation of a real-world location into a film, television show, novel or other form of popular culture. From mainstream franchises like The Lord of the Rings and Harry Potter, to series with dedicated fanbases like Twin Peaks and Wallander, these initiatives have been analysed as examples of 'media-induced tourism' (see, e.g., Busby \& Klug, 2001; Gjorgievski \& Trpkova, 2012), 'contents tourism' (Seaton et al., 2017) and 'media pilgrimages' (see, e.g., Imai, 2005; Norris, 2013), among other concepts. Yet videogames remain largely overlooked in this field of research. In game studies and in media and cultural studies, scholars have investigated how the representation of real-world locations in series like Assassin's Creed and Grand Theft Auto compare with their fictional counterparts, through detailed comparisons of the physical and digital spaces (see Miller, 2008). But to date, apart from a handful of exceptions (Dubois \& Gibbs, 2018; Jaworowicz-Zimny, 2020; Sugawa-Shimada, 2015; Yamamura, 2018), few scholars have explored how this representation might carry over into the tourism campaigns and economic strategies of locales that appear in videogames.

This chapter addresses this gap through the case study of Yokosuka in Japan, which has recognised the cult classic videogame series Shenmue as a drawcard for tourists and fans from outside the city to visit its spaces. Through its Shenтие Sacred Spot Guide Map, Yokosuka officials provide a detailed guide for tourists seeking to visit locations depicted in the game. It contrasts with their fictional and real-world counterparts and invites visitors to explore the city through events and promotion campaigns tied to the map. Drawing on an analysis of the guide map, an interview with its creators and field observation in Yokosuka itself, we examine the potential for videogame pilgrimages to put cities otherwise overlooked in travel guides and reviews figuratively on the map and to boost their local economy. The chapter begins with an overview on the literature on popular culturedriven tourism, focusing particularly on contents tourism, which is of particular relevance to the Japanese context. The second part then outlines the Shenmue Sacred Spot Guide Map campaign, concentrating on the specific policy settings of 
Yokosuka and the growing role that contents tourism campaigns centred on popular anime and game franchises have come to play in its economic development. The final part then analyses three aspects of the guide map: the map's development; the promotion campaigns surrounding it; and its measurable impact, drawing on fieldwork research. The chapter concludes by reflecting on the Shenmue Sacred Spot Guide Map as an example of 'complex contents tourism' (Seaton et al., 2017). We argue that it carries valuable lessons for policymakers about incorporating videogames into local tourism initiatives, but its impact remains difficult to measure and replicate elsewhere because of the specific circumstances surrounding its creation and the franchise on which it is based.

\section{Incorporating videogames into tourism scholarship}

Government agencies at every level (local, state, regional, national and so forth) have long recognised the potential for media and popular culture texts that feature their localities to attract fans and tourists. Perhaps most famously, the national government-funded body Tourism New Zealand successfully capitalised on the success of The Lord of the Rings film trilogy to promote New Zealand, where the films were shot, as a tourist destination to travellers around the world. The campaign involved television and cinema spots, print advertisements, paid news features and media appearances from the film's cast, crew and New Zealand politicians. It culminated in the launch of the 100\% Middle-earth, 100\% Pure New Zealand campaign in 2012 (see Arnold, 2003; Jones \& Smith, 2005; Tourism New Zealand, 2013). Another example is the Seattle city government's official tourism website Visit Seattle, which has a dedicated webpage listing locales and businesses that feature in the television series Twin Peaks (Visit Seattle, n.d.). The Swedish town of Ystad has developed a detailed interactive map called In the Footsteps of Wallander, with information about 65 locations in and around the town that feature in the Wallander books and television series (Ystads kommun, n.d.). And the Brontë Society in Haworth, UK, runs the Brontë Parsonage Museum, providing VIP tours and offering information to visitors about the locations where the infamous Brontë sisters lived (Bronte Parsonage Museum, n.d.).

Philip Seaton et al. (2017) note that Japan has been particularly successful at embracing its popular culture - including film, novels, anime, manga, music and videogames - to attract international fans to its shores. Following the Cool Japan campaign that originated in the early 2000s, the Japanese government began to recognise the potential for tourism induced by popular culture as a key strategy for boosting its local tourism industry. This strategy has unfolded under the umbrella of 'contents tourism' (kontentsu tsürizumu) and been taken up across numerous levels of government and across both the public and private sectors in the country. Takayoshi Yamamura, building on Seaton et al. (2017), defines contents tourism as

a dynamic series of tourism practices/experiences motivated by contents (defined ... as 'information - such as narratives, characters, locations, and 
other creative elements - that has been produced and edited in popular culture forms and that brings enjoyment when it is consumed'). Contents tourists access and embody 'narrative worlds' that are evolving through 'contentsization', namely the continual process of the development and expansion of the 'narrative world' through both mediatized adaptation and tourism practice.

(Yamamura, 2020, p. 13)

Contents tourism thus differs from other forms of tourism mainly in that the traveller's motivation for visiting the site is driven by a connection to a particular popular culture phenomenon, rather than the distinct features of the site itself (such as its architecture, heritage value or geographic features) - although the locations they visit may also have these features. The traveller's motivation might be as specific as wanting to experience a location depicted in a film or as vague as wanting to experience the atmosphere of their favourite manga series.

Contents tourism, according to Seaton and Yamamura, is not a fleeting, smallscale initiative but a central strategy in the economic development of Japan that emerged out of a period of economic stagnation and population decline. The early 2000s, they note, marked 'a crucial shift away from the focus on manufacturing that had characterized the economic miracle in the second half of the twentieth century and placed the focus on Japan's creative industries' (Seaton \& Yamamura, 2015 , p. 5). Following an ambitious plan to attract 10 million international tourists a year to Japan by 2010 ,

the focus of national branding began the shift from traditional culture to a blend of traditional and pop culture . . contents tourism [is now] a cornerstone of Japan's economic plans for the coming decade and it is hoped by the government that [it] will generate massive additional revenues for Japan. The government has gone beyond thinking of contents as an export business, but rather now considers contents to be the first stage of a national strategy that invites tourists to visit Japan as the site where those contents originated.

(Seaton \& Yamamura, 2015, pp. 5-7)

Some contemporary examples of successful contents tourism campaigns in Japan include Capcom's partnerships with cities and corporations connected to its videogame Sengoku Basara; the Sanrio Puroland theme park in Tama, Tokyo, which regularly attracts fans of Hello Kitty; and Chōfu, Tokyo, which brands itself as the 'town of film' and allows self-guided tours around its film studios (see Seaton et al., 2017, pp. 34-35, 85-87, 147). Contents tourism as both a policy agenda and object of study remains centred on Japan, given that the term itself is a Japanese invention. But Seaton et al. point out that there are many examples of contents tourism in other countries as well, although they may be articulated via different concepts (2017, p. 8; see also Yamamura, 2020).

All the examples we have outlined so far involve government agencies at different levels officially supporting a tourism campaign through funding or resources, whether as their own initiative or in partnership with a content owner. Of course, 
there are also many examples where local small businesses, independent institutions and entrepreneurs have appropriated or taken advantage of popular culture texts that have a connection to their location in order to promote themselves. Guided tours, walks, themed cafés and in-store products and promotions often fit into this category (see, e.g., Norris, 2013). In addition, fans may embark on their own 'pilgrimages' to cities, towns, sites, buildings or landmarks featured in popular culture texts of their own accord, with only informal, fan-made guides rather than any officially sanctioned products or services informing their visit (see, e.g., Lombardi, 2018). Our case study of Shenmue itself started as a fan initiative, with examples from as early as that of Rodger Swan (Rodgerswan, 2008), one of the first YouTubers to share some of the iconic locations that would later appear on the Shenmue Sacred Spot Guide Map.

For the purposes of this chapter, however, we have chosen to focus our discussion specifically on contents tourism - that is, tourism motivated by the association of a popular culture text with one or more locations (Seaton et al., 2017, p. 4) that has been supported by a government agency in some way. This is because this type of tourism most closely relates to our case study of the Shenmue Sacred Spot Guide Map. The case study fits this description, as we shall outline next, and it is also situated in the Japanese city of Yokosuka, where contents tourism has been a key strategy of the city at the municipal level. Our narrower focus makes sense given this connection with the Japanese context and the broader history of contents tourism in Japan. However, contents tourism is a branch of cultural tourism (Seaton \& Yamamura, 2015, p. 4) and shares traits with other types of cultural tourism - for instance, media tourism, film-induced tourism and literary tourism (see Beeton, 2005; Busby \& Klug, 2001; Reijnders, 2011; Watson, 2006). Contents tourism also shares many similarities with the 'media pilgrimage', in which fans embark on a 'pilgrimage' to the 'sacred sites' of their favourite popular culture texts (see Couldry, 2000, 2007; Norris, 2013). While contents tourism remains a related but more specialised approach to these types, we nonetheless incorporate discussions from these fields where relevant. We also acknowledge the elusiveness of the term 'contents tourism', which as Seaton et al. note (2017, pp. 3-6, 36) can often involve numerous actors, patterns and motivations that can be difficult to differentiate from other types of tourism.

There is now a growing body of literature on contents tourism, with numerous journals and publications devoted to its study (see in particular the International Journal of Contents Tourism and Seaton \& Yamamura, 2015, Yamamura \& Seaton, 2020). Similarly, research on the aforementioned other forms of cultural tourism is growing. But the role of videogames in tourism initiatives remains underdeveloped, even though 'computer games' are specifically included in Seaton et al.'s (2017, p. 3) original definition of contents tourism. In contents tourism literature, apart from the example of Sengoku Basara (see Seaton et al., 2017, pp. 34-35; Sugawa-Shimada, 2015; Yamamura, 2018), there are only a handful of case studies on videogames. Most notably, Aleksandra Jaworowicz-Zimny (2020) discusses The Witcher series tourism in Poland, focusing primarily on the live-action role play (LARP) Witcher School. Through a survey of participants, 
Jaworowicz-Zimny found that LARP encouraged some participants to spend more time in Poland than they would otherwise, although this was expressed only through intention. But because The Witcher series is only inspired by the Polish landscape rather than set in any specific real-world locales, some participants questioned its connection to the game. Further, all The Witcher tourism events mentioned are organised by fans, companies and entrepreneurs, with little recognition from municipalities about The Witcher's tourism potential to date (Jaworowicz-Zimny, 2020).

Outside the field of contents tourism, scholars have likewise seldom examined how game texts are or might be used by businesses and organisations to attract fans to the locations they depict. One exception is the work of Louis-Etienne Dubois and Chris Gibbs (2018), which examines a small sample of online comments from players of the videogames Assassin's Creed II (2009) and Assassin's Creed Unity (2014) - set in Italy and Paris, respectively - who visited the realworld locations depicted in the game. They outline three main types of what they call videogame-induced tourists. These include serendipitous tourists, who visit a destination portrayed in the game by coincidence; general tourists, who are drawn to a specific location not because it is included in a game but who engage in gamerelated activities while there; and specific videogame-induced tourists, who travel to a destination primarily because it is featured in a game. Dubois and Gibbs identify various ways businesses and government organisations might capitalise on these types of tourists, such as themed events or guides about locations and historical figures featured in the games (2018, p. 194). But their chosen game examples are set in cities like Florence and Paris, which already attract large volumes of tourists, overlooking smaller destinations that might be able to more effectively capitalise on a niche audience of videogame fans to attract visitors (2018, p. 195).

In game studies, there are numerous analyses of videogame texts that compare and contrast virtual representations of cities and other locations in games like the Assassin's Creed and Grand Theft Auto series with the real-world environments they depict (see, e.g., Golding, 2014; Hakimi, 2016; Miller, 2008, 2012; Schweizer, 2014). But these discussions focus on how real-world physical locations are represented in the videogame text rather than on how this representation might have implications for the locations depicted themselves. This chapter helps fill this gap in the scholarly literature through the case study of the Shenmue Sacred Spot Guide Map, a unique example of contents tourism in the city of Yokosuka, Japan, that highlights the challenges and opportunities of videogame-driven contents tourism for less-frequented tourist destinations.

\section{The Shenmue Sacred Spot Guide Map}

Shenmue is a role-playing and adventure videogame series. Created and directed by a pioneer of arcade gaming and 3D graphics, Yu Suzuki, the first game was released in 1999 for Dreamcast and published by Sega. A sequel was first launched in 2001 for Dreamcast, only in Japan and in the European territory, and then in 2002 for Xbox, aimed at the North American market, France and the United Kingdom. 
Remastered editions of both games in the series were released in 2018 as Shenmue $I$ \& II for PlayStation 4, Xbox One and PC. Finally, a long-awaited sequel, Shenmue III, was released in 2019 after a successful crowdfunding campaign. It was developed by Yu Suzuki's own company Ys Net and published by Deep Silver. Although the first game sold well, its high development costs - between US\$47 and US\$70 million (Sheffield, 2011) - and the declining sales of the Dreamcast meant that the game did not recoup its production costs. Nonetheless, as one of several innovative games developed during a period of experimentation in the Dreamcast's final days (see Montfort \& Consalvo, 2012), the game acquired a cult status (Jones, 2016; Bailey, 2018).

Set in 1986, the first Shenmue is a story of mourning and revenge told with the grandiloquence of a martial arts B-movie and the relaxed pace and intimate gaze of a Yasujirô Ozu costumbrista drama. This is possible partly due to the combination of the continuous passage of time and the pseudo-agency of the nonplayable characters, which creates 'a clockwork world that, once powered up, will play itself' (Holmes, 2012, p. 114). As both Alexander Galloway (2006) and Dylan Holmes (2012) note, by casting the player as a participant in something larger than themselves, Shenmue made the player experience both humbling and personal. The player assumes the role of Ryo Hazuki, a young karate practitioner who embarks on a quest to avenge his father's death, killed in front of him by a Chinese martial arts master known as Lan Di. Shenmue has been praised for being 'a pioneer of the hyperrealistic urban game environment' (Schwartz, 2006, p. 314), for the deep characterisation of both its protagonist and nonplayable characters (Fencott, 2003), and for the attention to detail of its cozy, charming open world. This includes the ability to interact with almost every character and object in the game, a design approach referred to as full reactive eyes entertainment (FREE). This 'FREEdom' extends from the ability to converse with over hundreds of nonplayable residents following their daily routine (whose lives are extensively mapped, even down to their individual blood type) to opening any drawer and inspecting almost any item by hand (Reeves, 2019). But primarily the game is notable for the extreme delicacy with which it portrayed mundane aspects of Japanese culture of the late 1980s (see Méndez \& Ramírez, 2015; Wood, 2018; Hutchinson, 2019).

Yokosuka is not an image that first comes to mind when one thinks of Japan's representation in popular culture. Shenmue's Yokosuka is a port city seemingly in decline. The game's main hub area of Dobuita is home to a number of thriving businesses, but these are interspersed with shuttered storefronts. At night, drunken salary workers stagger home, gangs operate in alleyways and US sailors from the nearby US military base search for their evening's entertainment. Life in Shenmue's Yokosuka is sunk into the most absolute routine. This reflects the game's coming-of-age story, which centres on its protagonist's quest to break away from his place of origin and pursue a fate that leads him outside Japan and (in the most recent game) deep into rural China. There is also, however, a certain nostalgic tenderness in this slow-paced perception of everyday life, where boomboxes, arcade machines of pre-3D-era games (designed by Yu Suzuki himself) 
like Hang-on and After Burner and video karaoke machines represent the pinnacle of progress.

As Rachael Hutchinson (2019, p. 42) writes,

the designers of Shenmue led the global games industry in recreating realworld environments in the game space, using the streets of Yokosuka as not just their inspiration but their model for surprisingly accurate renderings of the suburb as the setting for the game's action.

Before Shenmue, 3D representations of real-life locations were still an emerging field in the videogame industry. Game settings often tended towards the fantastic: possible worlds without clear references in the actual world. Although every work of fiction is based to some extent on a wide variety of elements, like characters, locations and events taken from the real world, Yokosuka is one of the first attempts by a videogame company to offer an almost touristic experience of a virtual environment that is recognisable by those who inhabit and know it in the real world.

The first Shenmue is set entirely in a fictionalised version of Yokosuka near the end of the Showwa era (1926-1989), which marked the twilight of Japan's economic boom. The game recreates numerous locales from the city, including its main street, Dobuita; surrounding areas like the Nagaura port warehouses; the residential area of Sakuragaoka; and Route 16, the main highway leading into the city. The in-game locations of Dobuita and Sakuragaoka retain their real-world names, although their geography and specific locations like buildings and streets differ from their real-world counterparts. ${ }^{1}$

The real-world Yokosuka is located in the Kanagawa Prefecture of the Kantō region of Japan. It is approximately $50 \mathrm{~km}$ south of the centre of Tokyo, which is Japan's largest city, with a metropolitan population of 13.5 million (2015 census). Yokosuka's estimated population in 2020 is 390,000, and like many Japanese cities, it has been consistently experiencing population decline over the past two decades (see City of Yokosuka, n.d.; Japan for Sustainability, 2015). Yokosuka is renowned for its port activity, for the presence of the United States Fleet Activities Yokosuka, one of the largest US military bases in the country, and for being home to the Oppama industrial plant, where Nissan factories employ thousands of residents. Historically, Yokosuka is remembered as the area where US Commodore Matthew C. Perry docked his ships in 1853 to initiate diplomatic relations with the Tokugawa shogunate. Its main tourist attractions include the Mikasa Park, with its memorial warship and its statue of Marshal-Admiral Tōgō Heihachirō; Sarushima Island, the only natural island in Tokyo Bay; the Yokosuka Art Museum; and an annual curry festival celebrating the city's famous navy curry dish.

Yokosuka's population is declining as part of a broader process in Japan of 'regional shrinkage' (see Matanle et al., 2011). This process is driven by a combination of the country's overall population decline due to low birth rates and the growing concentration of the country's remaining population in its three major cities: Tokyo-Yokohama (which together form the most populated continuous 
urban area in the world, with 38 million inhabitants), Osaka and Nagoya. As the overall Japanese population shrinks and residents relocate to these cities, smaller municipalities diminish more rapidly relative to the country's overall depopulation rate. Yokosuka, situated a mere $30 \mathrm{~km}$ from Tokyo-Yokohama, must compete with this nearby megalopolis to attract tourists and economic investment outside of its key manufacturing industries and military facilities.

In this context, the City of Yokosuka's Culture, Sports, and Tourism Division has invested heavily in contents tourism since the mid 2010 s as a way to draw tourists from these large urban centres to its spaces and reinvigorate its economy. Some of these initiatives, promoted under the broad banner of subculture, have centred on anime and manga. These include events in collaboration with the creators of anime series set partly or wholly in Yokosuka, such as Tamayura, Arpeggio of Blue Steel and High School Fleet - as well as exhibitions (hosted inside the Mikasa warship museum) of works by Yokosuka-born artists Nobuyuki Fukumoto and Kazutaka Miyatake (see Gundam, 2015; Sugawa-Shimada, 2018; Yokosuka Travel Guide, 2016a, 2016b, 2017). But many of these subculture-focused contents tourism initiatives have also involved videogame franchises, including location-based mobile games.

This videogame-focused contents tourism began in 2014, when the Culture, Sports and Tourism Division approached Niantic, the developer of the locationbased augmented reality game Ingress, to host a series of Mission Day events that involve completing tasks at famous landmarks across the city (Ingress Mission Day Yokosuka, 2015). Throughout 2016, following the release of Niantic's Pokémon $G O$, the city then sponsored a number of Pokémon $G O$ promotions aimed at attracting visitors to tourist spots around the city (see Yokosuka Travel Guide, 2016c, 2016d, 2016e). These initiatives culminated in the City of Yokosuka's hosting Niantic's Pokémon GO Safari Zone event in 2018, winning the event over its neighbour Yokohama, which hosted the event last year. After complaints of overcrowding and congestion during the Yokohama event, Yokosuka was reportedly able to deliver a smaller-scale and better-managed experience (see Hanaway, 2018) - literally realising the city's strategy of drawing tourists away from its larger and more commonly frequented neighbours.

In addition to these location-based game events and promotions, the City of Yokosuka has held events and exhibitions for the videogames World of Warships and Azur Lane, including an exhibition and promotion campaign celebrating a crossover between the two series (Nelva, 2019; Yokosuka Travel Guide, 2016c). But perhaps the most unique example of the city's contents tourism strategy is its collaboration with Shenmue's original publisher, Sega, to develop the Shenmue Chapter One: Yokosuka - Sacred Spot Guide Map (hereafter shortened to Shenmue Sacred Spot Guide Map or guide map), a pamphlet that highlights various places of interest from the Yokosuka townscape of the late 1980s that Shenmue is set in. The guide was first published in December 2017 by the city's Tourism Planning Division and made available for free in English and Japanese versions at the City Hall Information Centre and various retail outlets. An updated version was published in 2018, to commemorate the release of the Shenmue I \& II HD 
remastered edition. This edition includes minor revisions to the text and features in-game images from the remastered version of Shenmue (see Figure 3.1).

The pamphlet combines key text and information about the game with useful information on the main tourist spots of the town, dedicating considerable space to Dobuita Street. When opening the pamphlet, the reader finds a beautifully illustrated display of information about Yokosuka and its main shopping street. The main centrefold displays a map of the coast of Yokosuka: from the port of Nagaura, a place that inspired the port location of Shenmue, to Midorigaoka, a residential area close to Dobuita Street that evokes the adjacent in-game neighbourhoods of Sakuragaoka and Yamanose. It also includes the highway, Route 16 , which features in a game sequence where Ryo must speed along the highway on his motorcycle to rescue his love interest of sorts, Nozomi. Left of this map is a slightly larger, zoomed-in map of the city centre, which depicts locales in and around Dobuita Street from the game, along with the names of their real-world counterparts. Below these two maps, occupying the bottom half of the pamphlet, are boxes of information about highlighted locations on the map and a collection of archive photos of the real-world Yokosuka taken in the 1980s (see Figure 3.2).

In the remainder of this chapter, we examine the Shenmue Sacred Spot Guide Map and its potential to attract fans of the Shenmue series to Yokosuka against

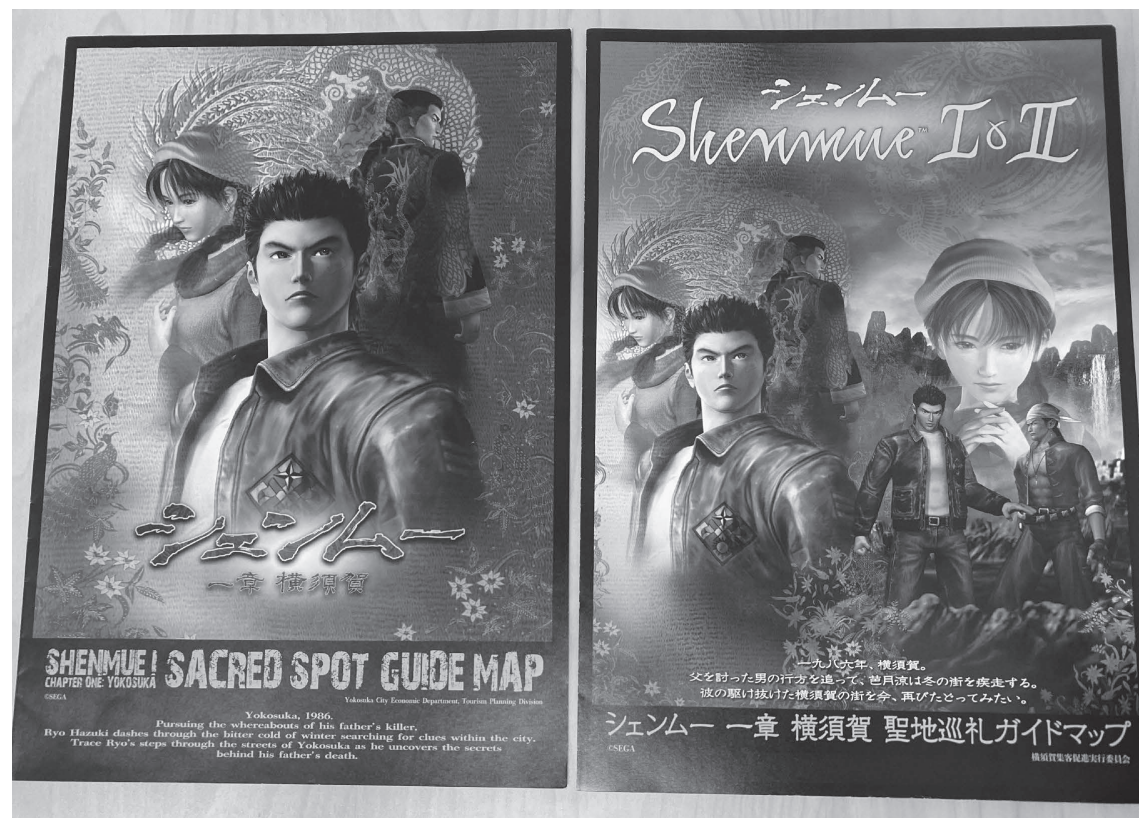

Figure 3.1 (Left) The 2017 English version of the guide map; (right) the 2018 Japanese version.

Source: photographs by Dale Leorke; guide map copyright 2017-2018 Sega/City of Yokosuka, used with permission 


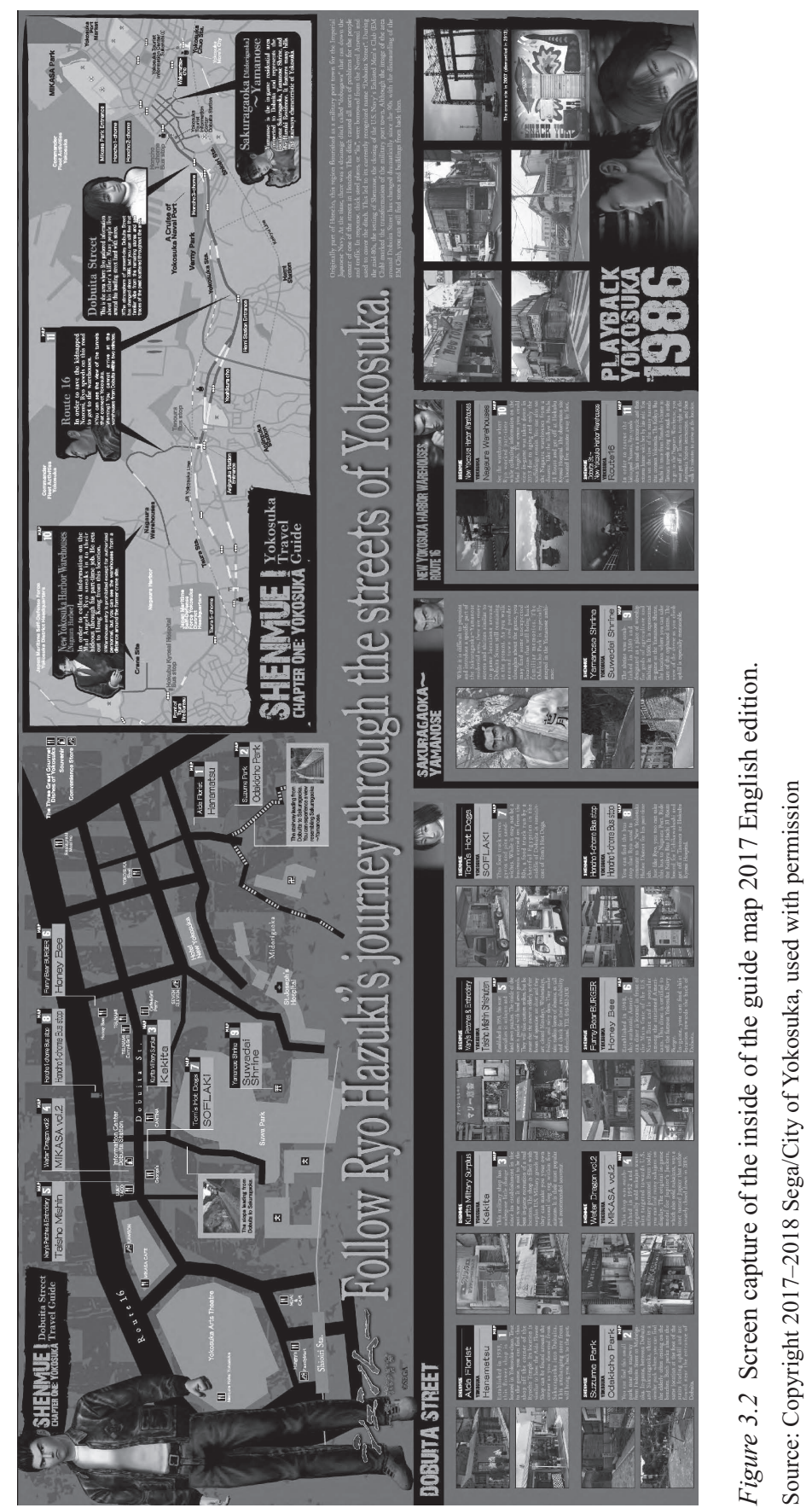


the backdrop of the city's broader contents tourism strategy aimed at countering its economic and population decline. This analysis is informed by the respective experience of its two coauthors. Ramírez-Moreno brings a deep knowledge of the Shenmue series, having written a book about it (see Méndez \& Ramírez, 2015) and closely analysed the game and accompanying guide map. Meanwhile, Leorke travelled to Yokosuka itself on 14 and 15 August 2019 to conduct original fieldwork for this chapter. This fieldwork involved visiting several locations listed on the guide map and interviewing its creators: Eriko Oyamada and Sae Sato. ${ }^{2}$ The trip was organised with the invaluable assistance of two Japanese researchers, Dr Ema Tanaka and Prof. Yuhsuke Koyama, both of whom joined the interview and fieldwork.

The interview was conducted on 15 August 2019 at the City of Yokosuka offices in both English and Japanese, using consecutive interpreting. ${ }^{3}$ It was recorded and transcribed into both English and Japanese by a professional transcriber fluent in both languages, and the transcript was provided to all present to verify its accuracy. Before the interview, Leorke, Dr Tanaka and Prof. Koyama also visited various locations that either feature in Shenтue or were recommended as tourist destinations on the guide map. During this fieldwork, they also conducted short informal interviews with three owners of the businesses that are listed on the guide map as influences for locations in the Shenmue game. These interviews were conducted in Japanese and translated on the spot into English by Dr Tanaka. This fieldwork lasted approximately 4.5 hours. (As we note in the acknowledgements, we owe a great debt to Dr Tanaka in particular for planning this fieldwork and acting as liaison and interpreter for the interview.) The evening before, Leorke also visited Dobuita Street alone. In Shenmue, the game's day-night cycle presents contrasting sides of Dobuita. By day, it is primarily a retail area for local residents. At night, the game emphasises its 'seedier' side, as a destination for US sailors to drink and gamble. Thus, it was important to visit the area during both daytime and nighttime to experience this contrast in reality.

In the following sections, passages that appear in italics are written by Leorke in the first person, adapted from his notes taken during the fieldwork in the city on both days. These observations and fieldwork notes were also informed by Leorke's experience with the Shenmue game, having completed it before visiting Yokosuka. Leorke acknowledges, however, that as a white Australian-born non-Japanese-speaking Westerner who spent only a relatively short time in the city - part of which was guided by Japanese colleagues from outside the city these observations must be read with the limitations of this perspective in mind.

\section{'Follow Ryo Hazuki's journey through the streets of Yokosuka'}

I arrive at JR Yokosuka-Chuo station in the early evening and head to Dobuita Street, only a short walk from my hotel, at around 9pm. At night, without the guide map in hand and feeling the self-consciousness of both a white Westerner in Japan and a tourist exploring an unfamiliar location in a 
foreign country, I struggle to make the connection between the streets before me and the night-time Dobuita of Shenmue familiar to me from my time spent with the game. Perhaps the most immediate connection between the two is the presence of US military personnel, who stand out due to their army uniforms and boisterous conversation. Some military personnel gather in small groups in front of the bars discussing their plans for the evening and greeting colleagues passing by, while others yell excitedly from inside bars or down the road. Although no specific locales from the game grab my attention, the winding street densely packed with store fronts, vending machines, apartment buildings and bars evokes the world of Shenmue, even as it could also stand in for almost any Japanese inner-city street-apart from the presence of US military personnel and more prevalent English signage.

(Leorke fieldnotes, 14 August 2019)

\section{Mapping the 'sacred spots' of Shenmue's Yokosuka}

The Shenmue Sacred Spot Guide Map was conceived of and developed by Eriko Oyamada, a web designer in Yokosuka's Tourism Division who has drawn on her strong interest in games to successfully advocate for the city's recognition of gaming culture. She initiated the city's collaboration with Niantic on its Ingress and Pokémon $G O$ events by approaching Niantic's office in Roppongi, Tokyo, and by creating a spot guide for Pokémon GO. She explains that the former mayor of Yokosuka is a fan of the original Shenmue, and after a conversation with him, they agreed to develop something to promote the city's connection with the game. In 2015, Shenmue's creator, Yu Suzuki, announced the aforementioned Kickstarter crowdfunding campaign for Shenmue III. This provided an impetus for the project, and Ms Oyamada contacted Sega for approval and began scouting locations to feature on the map with graphic designer Sae Sato throughout 2017 (City of Yokosuka interview, 15 August 2019; see also AniKaneda, 2018; Phantom River Stone, 2017).

The project was a partnership with Sega, who licensed the franchise rights and contributed some material to the final version, but the map itself was designed almost entirely by Ms Oyamada and Ms Sato. They describe a painstaking process of photographing locations around the city and comparing them with the virtual game environment to ensure they matched up (see Figure 3.3). Ms Oyamada explains that 'it took a lot of effort and many, many screenshots to get the right angle to help reflect the same image taken in the real-life location in Yokosuka' (City of Yokosuka interview, 15 August 2019). These detailed screenshots were not provided by Sega, and this process took place before the Shenmue I \& II HD remastered edition was released on contemporary game platforms, like the PS4, that include built-in screen capture tools. To capture these screenshots, they had to play the game on Dreamcast, which lacks such features and also does not include the ability to save and continue playing anywhere in the game, making it much more laborious. In this sense, although the initiative was sanctioned and supported from above by both the City of Yokosuka and Sega, its creation was a 


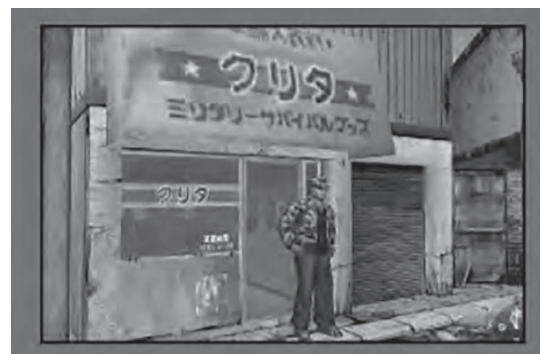

\section{SHENMUE \\ Kurita Military Surplus Yoknsukn \\ Kakita}

This military shop has undergone little change

MAP

3 since its establishment in the post-war era. It is said to be the best in-game recreation of a real location. The shop is filled with surplus U.S. Military goods and they can make you your own personal dog tag within five minutes. It is their most popular and recommended souvenir.

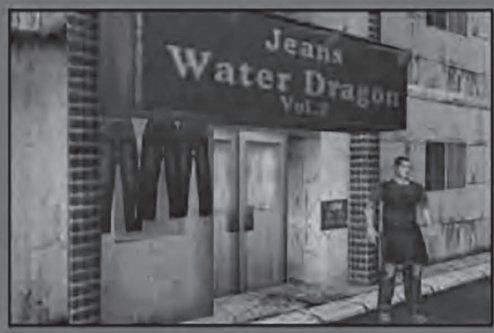

\section{SHENMUE}

\section{Water Dragon vol.2} Yokosuka MIKASA vol.2

This shop was established in 1952 and MAP originally sold sukajan souvenirs targeted towards U.S. military personnel. Even today, you can find many sukajans on display. The original in-game model for Jupitor's Jackets, which also sold sukajans, was a store named Jupiter that unfortunately closed down in 2015.

Figure 3.3 Detail of the guide map 2017 English version showing real-world vs in-game locations.

Source: Copyright 2017-2018 Sega/City of Yokosuka, used with permission 
'fan' project of sorts in itself - initiated and almost entirely undertaken by two city employees in their own time, fuelled by their own passion for the game rather than by financial gain.

For the locations depicted on the map, the level of similitude between the ingame and real-world counterparts varies. For some, the resemblance is clear: Hanamatsu, a historical florist established in 1933, is reminiscent of a flower shop owned by Aida, the grandmother of one of the game's recurring characters, Nozomi. Likewise, Kakita, a military shop established in the postwar era, immediately recalls Kurita Military Surplus, the in-game store run by Kurita-san; while MIKASA vol.2, established in 1952 and originally devoted to selling sukajan (souvenir jackets) to US military personnel, resembles the Water Dragon vol.2 store. In other cases, the similarities are less obvious or have diminished over time, so the creative team had to locate comparable locations in the current Yokosuka. One particular challenge was selecting locations representing the in-game neighbourhoods of Sakuragaoka and Yamanose, which players regularly visit throughout the game. As the guide map states,

While it is difficult to pinpoint and introduce a specific part of the Sakuragaoka Yamanose residential area, there are many streets and shrines similar to in-game locations around Dobuita Street still remaining in the present. As you walk around town and ponder thoughts about the game, you may find some unexpected locations that will bring back familiar memories. The Odakicho Park is especially steeped in the Yamanose ambiance.

(Shenmue Sacred Spot Guide Map 2017 edition text)

This varying degree of familiarity and dissonance between the in-game and realworld locales was evident in Leorke's own fieldnotes. As the fieldwork notes quoted at the beginning of this section demonstrate, the most immediately recognisable connection is the presence of US military personnel and the features of the urban landscape to accommodate them. This includes far more English signage than in other Japanese cities, such as street signs in English and signs warning US military personnel not to enter sacred sites like shrines or temples. Other locations, like the warehouse district and Suwadai Shrine (represented in-game as Yamanose Shrine), have a more tenuous connection to the game environment. The warehouses are not accessible to members of the public and can be viewed only from a distance across the harbour at the site of a dismantled crane. This is the first site that Leorke and his Japanese colleagues visit, taking a taxi from JR Yokosuka station along Route 16 - the same path that Ryo rides on his motorcycle to rescue Nozomi.

Dr Tanaka provides directions to the taxi driver, a serious and softly spoken man perhaps in his late 60s, showing him the recommended path outlined on the guide map. As we drive to the warehouse area, the driver mentions that many US military personnel who used to spend their weekend recreation time in Yokosuka now travel to Yokohama or Roppongi [a district in Tokyo 
popular with foreigners], reinforcing the city's economic decline. The driver notes that not many of his passengers ask to be taken to the warehouse district since it isn't accessible to the public. We arrive at the warehouse and park at a largely abandoned dirt area with a dilapidated building nearby. Apart from two workers at the building, who must wonder what we are doing there, no one else is around. The driver waits in the car while we take photos and take in the harbour view. As we do so, Ifeel a bit like a naïve tourist, visiting a completely mundane place and assigning it a significance that nobody else there shares. I take photos and try to invoke Shenmue's bustling docks in mind, but this feels like a dead zone that has little if any connection with the game.

(Leorke fieldnotes, 15 August 2019)

Because Yokosuka's role as a manufacturing and port hub has been diminishing since the 1980s, the port area has changed, with the site of the former crane now abandoned and the port's size visibly reduced from its glory days. Other locations have changed even since the guide map was produced:

When we attempt to visit SOFLAKI on Dobuita Street - a food truck selling Greek food that the guide map describes as 'reminiscent' of Tom's Hot Dogs from Shenmue - in its place is a 'Crazy Burritos'stand. We approach the owner and ask if SOFLAKI still exists, and he explains that it burned down several years ago (no one was injured or killed) and the shop owner has opened a new, permanent burger store down the road called Arabella. When we go there, we speak to the owner-a middle-aged woman with short, buzzcut hair and a very bubbly personality - who has never heard of the game or her former store's incorporation into it before. We had planned to lunch at Honey Bee's around the corner (the inspiration for Shenmue's Funny Bear BURGER). But when we see a massive queue to get a table at Honey Bee's, we accept her invitation to eat at her restaurant and hand her a Japanese version of the guide map. Now perhaps she can read about her store's strange, convoluted connection to the game.

(Leorke fieldnotes, 15 August 2019)

\section{Promoting Yokosuka's local economy through the guide map}

The initial print run of the map included 10,000 copies in Japanese and English, with approximately half of these distributed to the US naval base at Yokosuka. As Ms Oyamada explains, this was a strategy used by the City's International Relations Division to engage US military personnel - many of whom are 'relatively young and . . . interested in the Shenmue game' - to help promote the map to their US and international friends and relatives who may visit Yokosuka (City of Yokosuka interview, 15 August 2019). In addition to the physical guide map pamphlet, the Tourism Division has hosted a number of events and promotion campaigns to raise awareness of the guide map and the city's connection to Shenmue. These were 


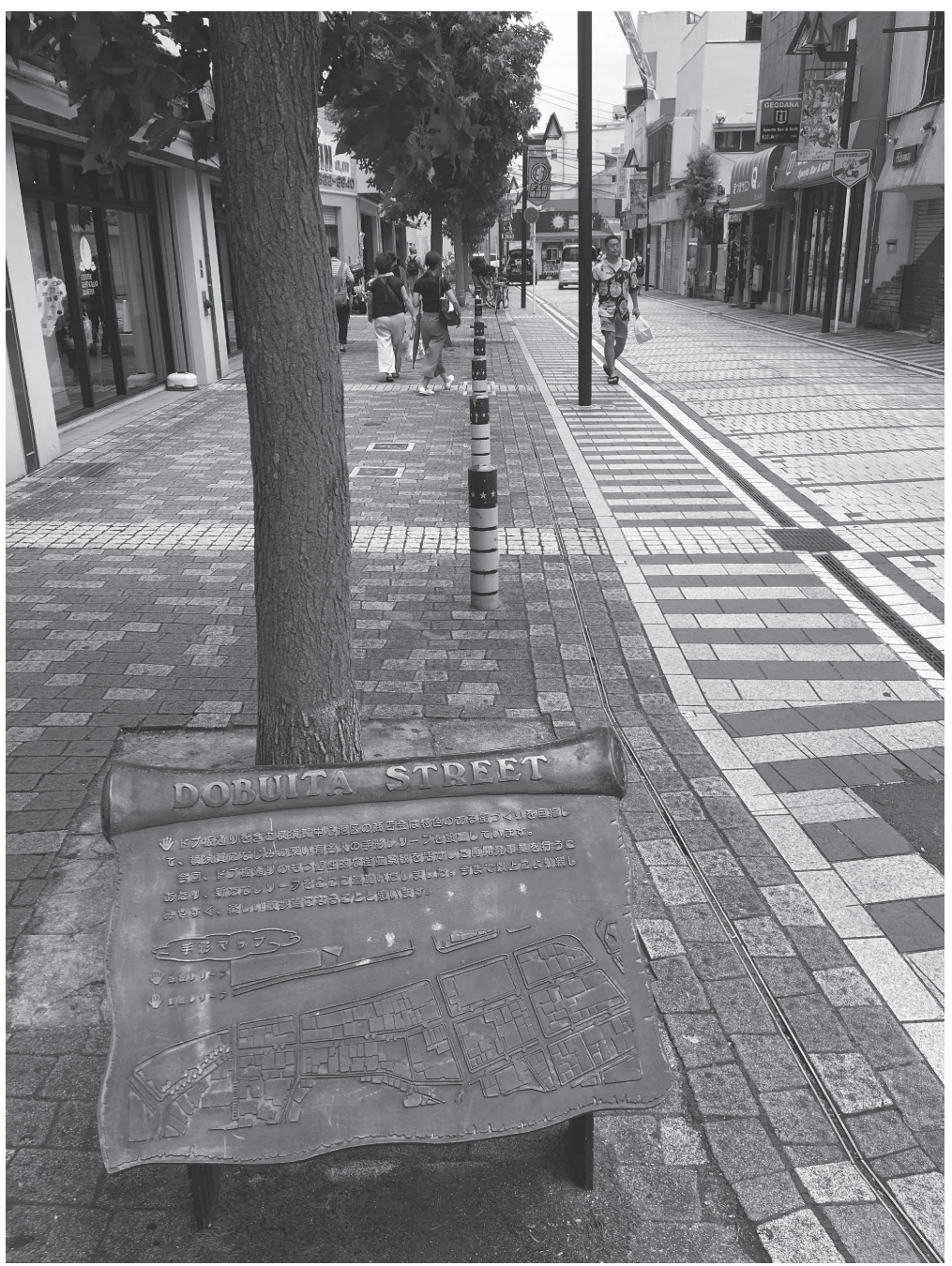

Figure 3.4 Dobuita Street, Yokosuka.

Source: photograph by Dale Leorke

particularly tied to the release of the Shenтие I \& II HD remastered versions in 2018. The updated version of the pamphlet featuring images from the remastered edition was distributed at Sega's booth at the Tokyo Game Show in 2018, and in December that year, the city also organised a Shenтue fan meeting at a live music bar in Yokosuka. The event, co-organised with IGN Japan, included 120 attendees randomly chosen from those who preregistered and featured onstage guests, such as Masaya Matsukaze, the Japanese voice and motion-capture actor for Ryo 


\section{Carlos Ramírez-Moreno and Dale Leorke}

Hazuki, and Eigo Kasahara and Hiroshi Noguchi, the planning director and motion camera and animation coordinator respectively, of the original Shenmue. Other guests came directly from Yokosuka, such as the owner of Kakita which inspired the game's Kurita Military Surplus store (see Phantom River Stone, 2018).

Between December 2018 and February 2019, the city also ran a campaign to encourage tourists to complete the route of shrines, parks and stores featured in Shenmue. The city placed several Shenmue-themed stands around Dobuita and distributed a series of original drink coasters featuring character artwork from the game to several of the shops featured on the guide map. Each

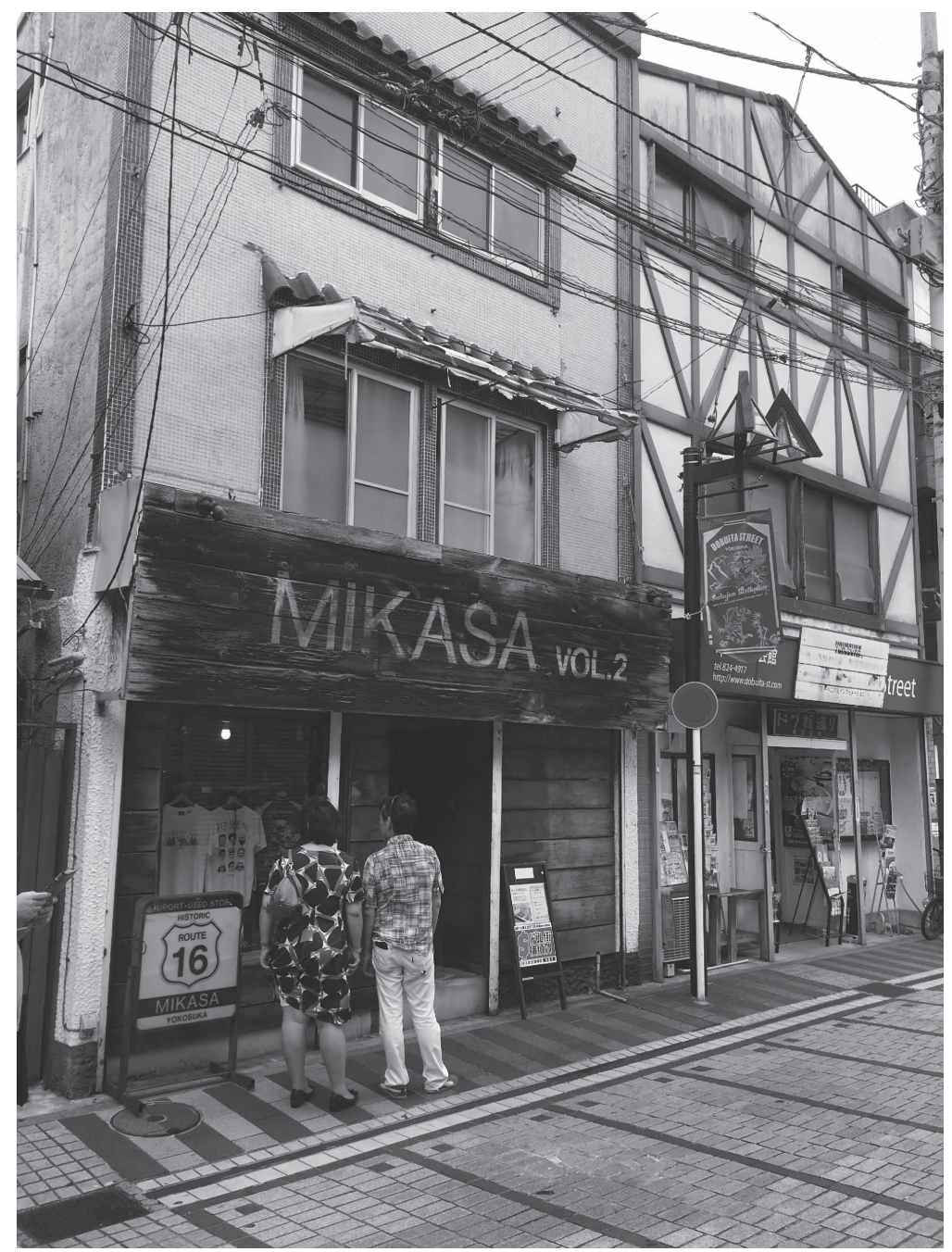

Figure 3.5 MIKASA vol.2 store, Dobuita Street, Yokosuka.

Source: photograph by Dale Leorke 
visitor who spent at least $¥ 500$ in those stores received one of the coasters as a gift. Ms Oyamada says that 'according to the stores who were participating, about half the coasters were received by foreigners that were living in Japan. So it was very well received by people from abroad as well, not just Japanese customers'. She also claims that immediately following the guide map's publication, 'there was a lot of people, especially foreigners, that were walking around Dobuita street with the guide map' and posing for photographs in parks (City of Yokosuka interview, 15 August 2019).

Her claims align with the informal interviews that Leorke and his colleagues conducted with shop owners. They spoke to the owner of Kakita, the militarythemed clothing store; the owner explained that although not many Shenmue pilgrims had visited recently during the promotion campaign, there were large numbers. He mentioned the store was given posters of the game to sell, which have now all sold out. Similarly, the owners of MIKASA vol.2 also stated that most Shenmue fan visits occurred during the campaign and that during it many foreign residents brought their friends from outside the city. As noted earlier, the owner of the former SOFLAKI store had not heard of the game, but this is likely due to its tenuous connection.

Contents tourism can also bring negative consequences, such as visitors flocking to previously quiet neighbourhoods because of their historical or cultural features and disrespecting local customs. Inappropriate and insensitive behaviour, littering and harassing locals have been among the consequences of the Japanese government's policies aimed at boosting tourism to the country (McCurry, 2019). Videogame-driven tourism and fan pilgrimages can also contribute to this process. For instance, Persona is a Japanese role-playing series enormously popular in the West, which, like Shenmue, gives players a high degree of freedom in a meticulously re-created everyday Japanese setting. The latest game is set in Tokyo, and in 2018, the game's developer issued a statement warning pilgrims not to loiter in areas depicted in the game, like laundromats, cafés and supermarkets (Loveridge, 2018). Perhaps because of the guide map's small scale and the game's cult status, however, we are not aware of any such incidents caused by Shenmue pilgrims or users of the guide map. Although a full survey of residents and store owners in the areas depicted is beyond the scope of this chapter, the guide map's creators and the store owners whom we spoke to did not report such incidents. Ms Oyamada states that 'a lot of the Shenmue fans were actually considered an older audience, so they're actually very well behaved, and we haven't really received any negative responses concerning this campaign' (City of Yokosuka interview, 15 August 2019).

\section{Yokosuka's Shenmue link as complex contents tourism}

As a small-scale, low-cost 'fan' initiative of sorts, the guide map has clearly generated interest from the game's niche fanbase and helped boost Yokosuka's presence as a tourist destination on the micro-level. Based on the anecdotal evidence quoted from the interviews presented earlier, we speculate that the guide map has primarily attracted what Dubois and Gibbs (2018) term 'general' tourists and 
tourists specifically travelling to Yokosuka for the guide map campaign, although a small number may also be serendipitous tourists who pick up the guide map at the information centre by chance.

But the guide map's actual direct impact on the city's economy and tourism is difficult to measure. The Tourism Division does not track the number of pamphlets taken by visitors (only the number distributed), nor has it conducted any research, such as surveys, on whether the guide map has encouraged people from outside the city to visit new locations or spend more time there than they would have otherwise. In contrast, the Tourism Division conducted a survey of participants in the Pokémon GO Safari Zone event and received 12,954 responses. Based on these responses, they used an analytics tool developed in-house by the city's Urban Development Department to calculate how much money visitors spent on purchases and transportation in the city. This determined that the event contributed $¥ 1.5$ billion (approx. US\$14.2 million) to the city’s economy (City of Yokosuka interview, 15 August 2019).

But even if the Tourism Division attempted a comparable analysis of the guide map - which at the time of our interview they had not - it would likely prove fruitless. The city's other subculture-themed contents tourism initiatives are mostly tied to a particular event with a specified duration, such as the one-day Safari Zone or the anime exhibitions that are held over several weeks. The Shenmue Sacred Spot Guide Map differs in that visitors can pick it up at any time and visit any number of destinations featured on the map. It is also affiliated with an older franchise, which, despite being recently 'revived' by the release of the remastered edition and Shenmue III, is recognisable mostly as a classic or cult rather than mainstream franchise. There are certainly detailed documented examples of 'pilgrims' from abroad travelling to Yokosuka specifically to visit locations from the game, both before and after the guide map's publication (see, e.g., AniKaneda, 2018; Lewis, 2014; Phantom River Stone, 2017; Robinson, 2015; Wright, 2019). ${ }^{4}$ But it would be particularly difficult for the Tourism Division to determine how many users of the guide map travelled to Yokosuka or locations featured on the map because of their connection to Shenmue rather than as part of their general tourism in the city.

As we noted in the first section, this is a challenge for analyses of contents tourism generally, which despite its focus on the 'contents' of a media text can be difficult to differentiate from other, more easily identifiable forms of tourism. The actual economic impact of the Shenmue Sacred Spot Guide Map, then, is likely minimal compared even with Yokosuka's other contents tourism initiatives in partnership with franchises like World of Warships or High School Fleet, which attract hundreds or thousands of dedicated fans. As Ms Oyamada states, the guide map's primary economic value is 'in terms of PR and in terms of promotion' (City of Yokosuka interview, 15 August 2019). At the same time, the actual cost to the City of Yokosuka for creating the guide map was also minimal. Ms Oyamada notes that the annual licensing fee paid to Sega for the rights to Shenmue is 'much, much lower' than that for One Piece, for example, 
which was the current contents tourism campaign running during Leorke's visit to Yokosuka.

In this light, the Shenmue Sacred Spot Guide Map is a perfect example of the process that Seaton et al. (2017, p. 36) describe as 'complex contents tourism'. The guide map itself involves the use of a cult franchise resurrected almost two decades after the release of the last game in the series through an HD rerelease and a crowdfunded sequel. This provides a unique backdrop for the campaign: a period of reinvigorated interest in a slightly obscure series that has at best achieved modest commercial success and recognition from a dedicated fanbase. The campaign involves a series of small-scale initiatives driven from the bottom-up by city workers who are themselves fans of the game. But it has also been embraced at the top level by the former mayor, a fan of Shenmue, and by the current mayor - who has invested in subculture more broadly as part of what Ms Oyamada states is a strategy 'to make the city of Yokosuka a city of music, sports and entertainment' and who, as a former band member himself, recognises the economic potential of popular culture (City of Yokosuka interview, 15 August 2019). Thus, the guide map circulates in this complex environment, alongside Yokosuka's multilayered tourism initiatives, which encompass anime and videogame franchises and the city's military history and food culture - all of which overlap, intersect and intermingle in 'a complex and diverse tourism industry’ (Seaton et al., 2017, p. 36). The Shenmue Sacred Spot Guide Map circulates in this environment: it is one unique, easily overlooked component of the city's broader strategy to attract tourists and investment as it transitions from a manufacturing and military hub to a services-driven creative economy.

\section{Conclusion}

Before Dr Tanaka, Prof. Koyama and I depart Dobuita Street for our scheduled interview, there is one last destination on the guide map I want to track down: Suwadai Shrine, established in 1380, which appears in the game as Yamanose Shrine. We begin at the bottom of the 'slope leading from Dobuita to Sakuragaoka' identified on the guide map, which in the game connects the two neighbourhoods. In reality, it is actually a steep hill off the main street of Dobuita surrounded by residential buildings. After we clamber up a set of broken, uneven steps leading up the hill - not without difficulty in the intense summer humidity - we follow a dirt path leading to a park I suspect houses the shrine. Instead, we find an abandoned opening seemingly no one has visited in years, overgrown with weeds and swarming with insects. Sweating and incredibly tired from the climb, we spot the shrine below us, on the other side of this strange urban mini-forest. It turns out the entrance is not via the slope, as the guide map seemed to suggest, but from another small street off Dobuita. We make our way down there and take some photos, although it does not evoke strong memories for me of the Shrine that features in the game. 
Unlike the examples of media and cultural tourism campaigns supported by government agencies that we opened this chapter with - like 100\% Middle-earth, $100 \%$ Pure New Zealand or the Town of Film in Chōfu - the Shenmue Sacred Spot Guide Map is unlikely to have a significant economic impact. The aforementioned examples are linked to cultural products capable of mobilising thousands of fans from around the world and quickly and effectively commodified to meet the expectations of the most demanding fans. Even as an example of videogamedriven tourism, the guide map is a unique case for the reasons we noted earlier: the game's obscurity; the campaign's ongoing nature involving multiple, dispersed locations; and its grassroots creation with minimal direct input from the city or the game's publisher.

Nonetheless, the guide map is a strong example of a focused, locally crafted contents tourism campaign that attracts a modest number of local fans and international tourists already planning a trip to Japan, who might also include Yokosuka on their itinerary. This aligns with the city's subculture strategy, aimed at drawing in visitors from nearby tourist magnets like Tokyo, Yokohama and Kamakura. Therefore, the guide map's aim is not part of a national strategy aimed at attracting tourists to Japan or even attracting them to the Greater Tokyo Area, but one arm of Yokosuka's local efforts aimed at attracting new visitors to its spaces. Its small localised scale has also made it low cost for the city and helped it avoid the negative consequences of other popular culture tourism campaigns. These conditions might be present in other local economies that feature in videogames and could draw on the Shenmue Sacred Spot Guide Map as a case study. But the factors surrounding the guide map are quite specific and complex, making it difficult to replicate elsewhere.

As the interview and fieldwork reveal, this complexity extends to the recreation of locales from the game in the guide map itself. Dobuita Street and several shops, like Kakita and MIKASA vol.2, exhibit a strong, obvious connection to the game. But several of the locations featured on the guide map - the warehouse district, the former SOFLAKI store and Suwadai Shrine - are more symbolically or historically linked to the game than independently recognisable in present-day Yokosuka. Visiting them, for some fans, may be an important part of their pilgrimage to experience all the locations of the game. But for the authors of this chapter, it often reflects the misdirected imposition of the 'tourist gaze' (Urry, 1990) onto areas whose connection to the game had vanished, if it ever existed. Future research on this case study could analyse the online accounts of Shenmue pilgrims to Yokosuka or conduct surveys of guide map users to unpack in greater detail the synergies between the fictional and real-world locations it features. But this chapter focused primarily on the creation of the map itself and its incorporation into the city's broader cultural and economic policy. In doing so, we aimed to highlight and unpack one unique example of a videogame text whose potential for boosting tourism has been supported through urban policy at the micro-level. 


\section{Acknowledgements}

The fieldwork component of this research was funded by the Centre of Excellence in Game Culture Studies at Tampere University, Finland. We express our gratitude to Frans Mäyrä and Olli Sotamaa for recognising the unique value of this research and making the fieldwork possible during a trip to Japan for the DiGRA 2019 conference. We also thank members of the Game Lab at Tampere University for their detailed feedback on multiple drafts of this work and Philip Seaton for his incredibly helpful comments, particularly relating to our use of contents tourism concepts.

The fieldwork would also not have been possible without the generous assistance of Ema Tanaka. Not only did Dr Tanaka facilitate our contact with the Culture, Sports and Tourism Division, but also when Leorke's plans to arrange an interpreter fell through, she kindly agreed to join him in Yokosuka, act as his interpreter and help secure Robert Sato as an interpreter for Eriko Oyamada and Sae Sato. She also planned a packed a day of travel throughout Yokosuka, which involved arranging taxis, a ferry trip and museum visit. Our deepest thanks go to Dr Tanaka, in particular, and Yuhsuke Koyama for making this research so successful and special. We also thank Eriko Oyamada and Sae Sato for their time and invaluable insights into the guide map's creation and Robert Sato for acting as interpreter on their behalf.

\section{Notes}

1 Only the first Shenmue game is set in Yokosuka. The sequels are set primarily in Hong Kong and a fictional village located in an arguably Japanised version of Guilin, Guangxi Zhuang Autonomous Region in China (see Liang, 2019).

2 At the time of the interview, Ms Oyamada was known as Eriko Furusaki. In this chapter, we retrospectively refer to her by her current name. Note that in online articles about the guide map that we reference in this chapter, her former name is used.

3 The questions were primarily posed in English by Leorke, with some additional questions asked by his Japanese colleagues Dr Tanaka and Prof. Koyama. Leorke's questions in English were first translated into Japanese by Dr Tanaka. The two interviewees, Eriko Oyamada and Sae Sato, responded in Japanese, with their responses translated into English by Robert Sato, the coordinator of international relations at the City of Yokosuka. In both cases, consecutive interpreting was used, whereby the speaker paused every few moments to allow the interpreter to translate their statements into the relevant language. A list of questions was also translated into Japanese by Dr Tanaka and provided to the interviewees in advance, although this document was used more as a guide than as a strict programme.

4 The focus of our chapter is on the municipal recognition of Shenmue as a drawcard for tourism, so an analysis of these fan 'pilgrimages' is outside the scope of this chapter. Although the guide map's creators do not explicitly identify this previous work of fans as a trigger for the idea behind the campaign, it is undeniable that these 'pilgrims' have been cultivating the image of the city for years by creating online communities where Yokosuka has been unconsciously promoted as a place of devotion. Through blogs and YouTube videos, these fans have documented the city with no more resources than their thorough knowledge of Shenmue's street layout, drawing parallels between the physical 
and fictional image of the place. Drawing on Macgregor Wise (2008, p. 40), this is an example of foreigners' pulling cultural products instead of pushing them from the Japanese perspective. To a certain extent, this is true of the case study of this chapter: early Shenmue pilgrims initially pulled Yokosuka as a cultural product, thanks to their knowledge of it through the videogame, until the city's authorities began to push it for consumption by visitors from outside the city as part of their contents tourism strategy.

\section{References}

AniKaneda. (2018). Shenmue, Yokosuka, real life places \& interview with spot guide map co-creator Ms. Eriko Furusaki. Retrieved from www.anikaneda.com/index.php? tid $=7 \&$ pid $=60$

Arnold, E. (2003). Campaign: 'The Lord of the rings' puts New Zealand on the map. PR Week. Retrieved from www.prweek.com/article/1249201/campaigns-the-lord-rings-puts-newzealand-map

Bailey, K. (2018). Shenmue remains a cult classic and a cautionary tale. USgamer. Retrieved from www.usgamer.net/articles/shenmue-remains-a-cult-classic-and-a-cautionary-tale

Beeton, S. (2005). Film-induced tourism. Bristol: Channel View Publications.

Brontë Parsonage Museum. (n.d.). About us. Retrieved from www.bronte.org.uk/about-us

Busby, G., \& Klug, J. (2001). Movie-induced tourism: The challenge of measurement and other issues. Journal of Vacation Marketing, 7(4), 316-332.

City of Yokosuka (n.d.). Yokosuka City estimated population [Japanese]. Retrieved from https://www.city.yokosuka.kanagawa.jp/0830/data/toukei/suikei/now.html

Couldry, N. (2000). The place of media power: Pilgrims and witnesses of the media age. London: Routledge.

Couldry, N. (2007). On the set of the sopranos: 'Inside' a fan's construction of nearness. In J. Gray, C. Sandvoss, \& C. L. Harrington (Eds.), Fandom: Identities and communities in a mediated world (pp. 139-148). New York: New York University Press.

Dubois, L., \& Gibbs, C. (2018). Video game - induced tourism: A new frontier for destination marketers. Tourism Review, 73(2), 186-198.

Fencott, C. (2003). Agencies of interactive digital storytelling. In Proceedings of TIDSE 2003, Darmstadt. Retrieved from www.fencott.com/Clive/TU/research/AgenciesofIDS.pdf

Galloway, A. R. (2006). Gaming: Essays on algorithmic culture. Minneapolis: University of Minnesota Press.

Gjorgievski, M., \& Trpkova, S. M. (2012). Movie induced tourism: A new tourism phenomenon. UTMS Journal of Economics, 3(1), 97-104.

Golding, D. (2014). Moving through space and time: A genealogy of videogame space (Doctoral dissertation), The University of Melbourne, Melbourne.

Gundam. (2015). The 'mechanical designer Kazutaka Miyatake Exhibition' opens at the museum ship Mikasa. Retrieved from https://en.gundam.info/news/event/news event_20151008_49618p.html

Hakimi, J. (2016). Playing Los Angeles itself: Versions of and from the historical city in L. A. Noire and the 'semi-documentary' Noire. Wide Screen, 6(1).

Hanaway, T. (2018). Video gamers from across Japan, and the world, put down their controllers and head to Yokosuka. Japan Times. Retrieved from www.japantimes.co.jp/ news/2018/09/08/national/media-national/video-gamers-across-japan-world-put-con trollers-head-yokosuka/\#.Xh2wOVMzY8Z

Holmes, D. (2012). A mind forever voyaging: A history of storytelling in video games. Scotts Valley, CA: CreateSpace. 
Hutchinson, R. (2019). Japanese culture through videogames. London and New York: Routledge.

Imai, N. (2005). Anime "Sacred Place Pilgrimages": The potential for bridging traditional pilgrimage and tourism activities through the behavior of visitors to anime "sacred places". University of Hokkaido Cultural Resources Management Annals, 11, 1-22.

Ingress Mission Day Yokosuka. (2015). English info. Retrieved from http://ingressyoko suka.blogspot.com/p/english.html

Japan for Sustainability. (2015). Japan's depopulating society: Population concentration in Tokyo and the disappearance of local municipalities (part 1). Retrieved from www. japanfs.org/en/news/archives/news_id035298.html

Jaworowicz-Zimny, A. (2020). The Witcher novels and games-inspired tourism in Poland. In T. Yamamura \& P. Seaton (Eds.), Contents tourism and pop culture fandom: Transnational Tourist experiences (pp. 46-61). Bristol: Channel View Publications.

Jones, D., \& Smith, K. (2005). Middle earth meets New Zealand: Authenticity and location in the making of The Lord of the Rings. Journal of Management Studies, 42, 923-945.

Jones, W.(2016). Exploring thestrangeworldof'Shenmue'fandom. Vice. Retrieved fromwww. vice.com/en_uk/article/7bd54y/exploring-the-strange-world-of-shenmue-fandom-042

Lewis, R. (2014). A Shenmue pilgrimage: Visiting the scenic real-life locations from Sega's game. Venture Beat. Retrieved from https://venturebeat.com/community/2014/09/07/ shenmue-a-gamers-pilgrimage/

Liang, L. (2019). Shenmue 3: The view from Guilin. Eurogamer.net. Retrieved from www. eurogamer.net/articles/2019-12-12-shenmue-3-the-view-from-guilin

Lombardi, L. (2018). Anime is turning quiet corners of the world into major tourist attractions. Polygon. Retrieved from www.polygon.com/2018/12/12/18129103/ anime-tourism-japan-your-name

Loveridge, L. (2018). Staff ask persona 5 pilgrims to mind their manners. Anime News Network. Retrieved from www.animenewsnetwork.com/interest/2018-06-28/staff-askpersona-5-pilgrims-to-mind-their-manners/.133473

Macgregor Wise, J. (2008). Cultural globalization: A user's guide. Hoboken, NJ: Blackwell.

Matanle, P., Rausch, A. S., \& Shrinking Regions Research Group. (2011). Japan's shrinking regions in the 21st century: Contemporary responses to depopulation and socioeconomic decline. Amherst: Cambria Press.

McCurry, J. (2019). Geisha selfies banned in Kyoto as foreign tourism boom takes toll. The Guardian. Retrieved from www.theguardian.com/world/2019/nov/05/geisha-selfiesbanned-in-kyoto-as-foreign-tourism-boom-takes-toll

Méndez, R., \& Ramírez, C. (2015). La Odisea de Shenmue [Spanish]. Sevilla: Héroes de Papel.

Miller, K. (2008). The accidental carjack: Ethnography, gameworld tourism, and grand theft auto. Game Studies, 8(1). Retrieved from http://gamestudies.org/0801/articles/miller

Miller, K. (2012). Playing along: Digital games, youtube, and virtual performance. Oxford: Oxford University Press.

Montfort, N., \& Consalvo, M. (2012). The Dreamcast, console of the avant-garde. Loading . . The Journal of the Canadian Game Studies Association, 6(9), 82-99.

Nelva, G. (2019). Azur Lane and world of warships invade Yokosuka. Twinfinite. Retrieved from https://twinfinite.net/2019/05/azur-lane-world-of-warships-yokosuka/

Norris, C. J. (2013). A Japanese media pilgrimage to a Tasmanian bakery. Transformative Works and Cultures, 14, 1-16.

Phantom River Stone. (2017). Interview with Yokosuka city. Retrieved from www.phan tomriverstone.com/2017/12/interview-with-yokosuka-city-story.html 


\section{Carlos Ramírez-Moreno and Dale Leorke}

Phantom River Stone. (2018). Shenmue fan meeting in Yokosuka: Summary \& highlights. Retrieved from www.phantomriverstone.com/2018/12/shenmue-fan-meeting-in-yoko suka-summary.html

Reeves, B. (2019). Inside the Bizarre development of Shenmue III. Gameinformer. Retrieved from www.gameinformer.com/2019/11/06/inside-the-bizarre-development-of-shenmue-iii Reijnders, S. (2011). Places of the imagination: Media, tourism, culture. Farnham: Ashgate. Robinson, M. (2015). A postcard from Yokosuka: Retracing the steps of the original Shenmие. Eurogamer.net. Retrieved from www.eurogamer.net/articles/2012-11-23-shenmueretrospective

Rodgerswan. (2008). Tokyo swan 39: Real life Shenmue. Retrieved from https://youtu.be/ xfmDm_MKGv0

Schwartz, L. (2006). Fantasy, realism, and the other in recent video games. Space and Culture, 9(3), 313-325.

Schweizer, B. (2014). Videogame cities in motion (Doctoral dissertation), Georgia Institute of Technology, Atlanta.

Seaton, P., \& Yamamura, T. (2015). Japanese popular culture and contents tourism - Introduction. Japan Forum, 27(1), 1-11.

Seaton, P., Yamamura, T., Sugawa-Shimada, A., \& Jang, K. (2017). Contents tourism in Japan: Pilgrimages to 'sacred sites' of popular culture. Amherst: Cambria Press.

Sheffield, B. (2011). GDC 2011: Yu Suzuki: 'Sega will probably let me make Shenmue 3'. Gamasutra. Retrieved from www.gamasutra.com/view/news/33329/GDC_2011_Yu_ Suzuki_Sega_Will_Probably_Let_Me_Make_Shenmue_3.php

Sugawa-Shimada, A. (2015). Rekijo, pilgrimage and 'pop-spiritualism': Pop-cultureinduced heritage tourism of/for young women. Japan Forum, 27(1), 37-58.

Sugawa-Shimada, A. (2018). Playing with militarism in/with Arpeggio and Kantai collection: Effects of shōjo images in war-related contents tourism in Japan. Journal of War \& Culture Studies, 12(1), 53-66. https://doi.org/10.1080/17526272.2018.1427014

Tourism New Zealand. (2013). New 100\% middle-earth, 100\% pure New Zealand campaign highlights special interest experiences. Retrieved from www.tourismnewzealand. com/news/new-100-middle-earth-100-pure-new-zealand-campaign-highlights-specialinterest-experiences/

Urry, J. (1990). The tourist gaze: Leisure and travel in contemporary societies. London: Sage.

Visit Seattle. (n.d.). The real twin peaks. Retrieved from https://visitseattle.org/seattlelocalist/play/the-real-twin-peaks/

Watson, N. J. (2006). The literary tourist. Basingstoke: Palgrave Macmillan.

Wood, T. (2018). Shenmue; Immersion. Hokinoto. Retrieved from https://hokinoto.com/ shenmue-immersion/

Wright, S. T. (2019). 'It feels like home': The Shenmue tourists making the Yokosuka pilgrimage. Electronic Gaming Monthly. Retrieved from https://egmnow.com/ it-feels-like-home-the-shenmue-tourists-making-the-yokosuka-pilgrimage/

Yamamura, T. (2018). Pop culture contents and historical heritage: The case of heritage revitalization through 'contents tourism' in Shiroishi city. Contemporary Japan, 30(2), 144-163.

Yamamura, T. (2020). Introduction: Contents tourism beyond anime tourism. In T. Yamamura \& P. Seaton (Eds.), Contents tourism and pop culture fandom: Transnational tourist experiences. Bristol: Channel View Publications.

Yamamura, T., \& Seaton, P. (Eds.) (2020). Contents tourism and pop culture fandom: Transnational tourist experiences. Bristol: Channel View Publications. 
Yokosuka Travel Guide. (2016a). Nobuyuki Fukumoto Yokosuka Zawa . . Zawa Exhibition [Japanese]. Retrieved from www.cocoyoko.net/event/zawazawa.html

Yokosuka Travel Guide. (2016b). High school fleet SD character badge campaign [Japanese]. Retrieved from www.cocoyoko.net/event/haifurikan.html

Yokosuka Travel Guide. (2016c). Yokosuka GO: Sarushima route Yokosuka GO discount [Japanese]. Retrieved from www.cocoyoko.net/event/yokosukaGosarushima.html

Yokosuka Travel Guide. (2016d). Yokosuka GO: Tokyo Bay Ferry Yokosuka GO discount [Japanese]. Retrieved from www.cocoyoko.net/event/yokosukaGOtokyowan.html

Yokosuka Travel Guide. (2016e). Enjoy real world games!: Play safely with ingress and Pokémon GO! [Japanese]. Retrieved from www.cocoyoko.net/event/literacy.html

Yokosuka Travel Guide. (2017). World of warships $x$ high school fleet collaboration exhibition [Japanese]. Retrieved from www.cocoyoko.net/event/wowsxhsf.html

Ystads Kommun. (n.d.). In the footsteps of Wallander. Retrieved from http://ystadskom mun.maps.arcgis.com/apps/MapTour/index.html?appid=8fdda12ef7e741148ee4c6ddae a49ee1 